\title{
Do Entropic Biodiversity Methods Outcompete Alternatives? ${ }^{\dagger}$
}

\section{William Bruce Sherwin}

Evolution and Ecology Research Centre, School of Biological Earth and Environmental Science, University of New South Wales, Sydney, NSW, Australia

+ Presented at the Entropy 2021: The Scientific Tool of the 21st Century, 5-7 May 2021; Available online: https://sciforum.net/conference/Entropy2021/.

Published: 5 May 2021

The journal 'Entropy' is full of elegant entropy/information approaches for all aspects of biology and medicine, from molecular interactions to landscape diversity. But do these methods work as well as (or better than) alternative methods? Often this is not evaluated by either simulation or empirical data, with some exceptions (e.g., [1]); here I concentrate on two newer evaluations:

Assessing frequency differentiation between groups, times or locations; I focus on the very popular Bray-Curtis measure and its entropic competitors. I assess Bray-Curtis' fit to several groups of criteria. First, it fits many basic requirements for any diversity measure. Secondly, I examine its independence from confounding effects. Finally, I look at its sensitivity to natural changes, threats, or management that affect underlying dispersal, adaptation, random change, or generation of novelty. If we can forecast a measure such as Bray-Curtis under various conditions, then we can evaluate effects of past events, and forecast effects of future management. I show that Bray-Curtis can be forecast from underlying biological processes, but that the forecasting ability is improved by converting it into closely related entropy/information measures.

Incorporating functional differences between the variants (e.g., DNA sequence, expression, morphology) into biodiversity measures. Past methods have met counterintuitive stumbling-blocks, such as negative diversity, and apparent differentiation depending heavily on variability within-group. Attempts to minimise these problems have resulted in measures with poor sensitivity to functional differences between variants - which the method was supposed to incorporate! A novel approach, based on three related entropy measures, avoids these counterintuitive problems [2].

\section{References}

1. Sherwin, W.B.; Chao, A.; Jost, L.; Smouse, P.E. Information theory broadens the spectrum of molecular ecology and evolution. Trends Ecol. Evol. 2017, 32, 948-963.

2. Chao, A.; Chiu, C.H.; Villéger, S.; Sun, I.F.; Thorn, S.; Lin, Y.C.; Chiang, J.M.; Sherwin, W.B. An attributediversity approach to functional diversity, functional beta diversity, and related (dis) similarity measures. Ecol. Monogr. 2019, 89, e01343.

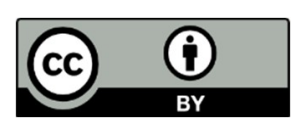

(C) 2021 by the author. Licensee MDPI, Basel, Switzerland. This article is an open access article distributed under the terms and conditions of the Creative Commons Attribution (CC BY) license (http://creativecommons.org/licenses/by/4.0/). 